\title{
12. AN EXAMINATION OF THE PALEOINTENSITY RECORD AND GEOMAGNETIC EXCURSIONS RECORDED IN LEG 155 CORES ${ }^{1}$
}

\author{
Stanley M. Cisowski² and Frank R. Hall ${ }^{3}$
}

\begin{abstract}
The normalization of the natural remanent magnetism to laboratory-induced remanence for discrete samples from the top $54 \mathrm{~m}$ of Hole 932A produces a pattern similar to the apparent variation of the geomagnetic dipole intensity for the period 10-80 $\mathrm{ka}$. Similar patterns in the shipboard archive-half intensity measurements for several other holes suggest that a paleointensity stratigraphy can be employed to date Leg 155 fan sediments. Two short intervals of anomalous field directions, or excursions of the geomagnetic field, have been identified in Hole 932A, at ages of $\sim 32 \mathrm{ka}$ and $\sim 43 \mathrm{ka}$, as determined from their positions within the intensity pattern. The younger excursion, which has been identified in nine Leg 155 holes, is best defined by discrete samples from Hole 930B. This excursion, which may correspond to the Lake Mungo Excursion, as recorded in aboriginal firepits in Australia, and sediment cores from the Gulf of Mexico, is characterized by short-lived ( $40 \mathrm{yr}$ ) synchronous peaks in inclination and intensity. The older Hole 932A excursion probably represents the Laschamp Excursion. Discrete sample analyses for Holes 942C and 946A revealed two other anomalous polarity intervals within interglacial Stage 5 . The younger excursion is associated with an interglacial carbonate layer representing Substage 5c. The older interval includes several short periods during which the field was nearly reversed, and may represent the Blake polarity event within Substage 5e.
\end{abstract}

\section{INTRODUCTION}

For most Ocean Drilling Program (ODP) legs, magnetic reversal stratigraphy is an invaluable tool in deriving the detailed chronology of the recovered sediments. This is particularly true when fossil test preservation is poor, or where paleontological markers are sparse. Because high sedimentation rates were expected for the Amazon Fan drilling sites, we anticipated that our magnetostratigraphic efforts might be confined to identifying short periods of anomalous polarity within the Brunhes normal chron, which might correlate with dated excursions and events reported from other areas. A distinct advantage of the extremely high sedimentation rates within the fan environment is the production of highly detailed records for these short-lived anomalies, facilitating correlation of the same feature between sites.

In the course of the Leg 155 shipboard paleomagnetic measurements, we observed a pattern in the archive-half remanence intensity curve that repeated at a number of sites (Flood, Piper, Klaus, et al., 1995, "Site 933" chapter, fig. 15). Because these archive core measurements were not normalized to any laboratory-induced remanence, it was not clear whether this pattern was because of synchronous changes in sediment character across the fan, or due to changes in the strength of the geomagnetic field with time. Therefore, a high priority of the post-cruise paleomagnetic research was to compare normalized paleointensity data for discrete samples to the continuous, archive core measurements.

\section{PROCEDURES}

Standard ODP-sized $\left(6 \mathrm{~cm}^{3}\right)$ paleomagnetic samples were taken at $\sim 20$-cm intervals over the top $\sim 30 \mathrm{~m}$ of advanced piston core (APC)

${ }^{1}$ Flood, R.D., Piper, D.J.W., Klaus, A., and Peterson, L.C. (Eds.), 1997. Proc. ODP, Sci. Results, 155: College Station, TX (Ocean Drilling Program).

${ }^{2}$ Department of Geological Sciences, University of California, Santa Barbara, CA 93106-9630, U.S.A. cisowski@magic.ucsb.edu

${ }^{3}$ Graduate College of Marine Studies, Robinson Hall, University of Delaware, Newark, DE 19716-3501, U.S.A. from Hole $932 \mathrm{~A}$ and the top $\sim 15 \mathrm{~m}$ of Hole $942 \mathrm{~A}$. Archive-half measurements for these intervals in both holes had given similar, welldefined intensity patterns (Flood, Piper, Klaus, et al., 1995, "Site 933" chapter, fig. 15; "Site 942" chapter, fig. 19). The upper portions of these holes were also chosen for discrete sample analysis because they consist of condensed hemipelagic sections overlying abandoned channel levee crests. Natural remanent magnetization (NRM) before and after alternating field (AF) demagnetization to 25 millitesla (mT) was measured for each sample on a Molspin sample magnetometer. Static AF demagnetization along three orthogonal axes was accomplished on a 2G Enterprises sample degausser. Each sample was then given an anhysteretic remanent magnetism (ARM) through simultaneous exposure to a $0.1-\mathrm{mT}$ DC field and a 100-mT AC field directed along the bedding plane. The resulting ARM was also measured before and after AF demagnetization to $25 \mathrm{mT}$.

Special "cuvette" samples of $1-\mathrm{cm}^{3}$ volume were taken at $2-\mathrm{cm}$ intervals across sections of core that exhibited anomalous declination and inclination values during shipboard archive-half pass-through measurements. These included Cores 155-930B-10H, 932A-3H, $942 \mathrm{C}-3 \mathrm{H}$, and 946A-15H. Only the first two cores were oriented azimuthally with a downhole Tensor tool. The NRMs of these samples were measured on a $2 \mathrm{G}$ cryogenic magnetometer, after AF demagnetization at $10,25,35$, and $45 \mathrm{mT}$. A few pilot samples were also demagnetized to higher AF values, but repeat demagnetization above $45 \mathrm{mT}$ often produced disparate directions and intensities of remanence. Several samples were also subjected to thermal demagnetization, either without previous AF treatment, or after AF demagnetization to $25 \mathrm{mT}$. For the thermal experiments, we employed the continuous heating method, whereby the sample is measured while still at progressively higher temperatures. Samples that were not thermally demagnetized were given a 0.1-mT ARM, and measured before and after AF demagnetization to $25 \mathrm{mT}$ on the Molspin magnetometer. Calibration experiments on the Molspin and cryogenic magnetometers indicated intensity variations of no more than a few percent between instruments for a wide range of remanence intensities.

The low field susceptibilities of all $6-\mathrm{cm}^{3}$ and $1-\mathrm{cm}^{3}$ samples were measured on a Geofyzika Brno KLY-2 Kappabridge susceptibility bridge. The Leg 155 post-cruise magnetic studies reported here were 
done at the University of California at Santa Barbara paleomagnetic laboratory.

In general, the remanence of the Amazon Fan sediments is dominated by intermediate-sized to fine-grained magnetite and titanomagnetite, with a minor canted antiferromagnetic (hematite) component. Except for limited occurrences of bacterial magnetite and iron sulfide nodules and crust, the bulk of the Leg 155 magnetic grains are primary, originating from Andean igneous and metamorphic provinces. No significant dissolution effects were apparent in any of the Leg 155 holes.

\section{RESULTS}

Figures $1 \mathrm{~A}$ and $1 \mathrm{~B}$ compare the demagnetized NRM/ARM intensity results for the $6-\mathrm{cm}^{3}$ discrete samples from Hole 932A to the paleointensity curve derived from stacked Mediterranean cores of ages 8-80 ka (Tric et al., 1992). Letters A-I, L1, and L2, delineate the series of intensity peaks and lows that were observed in the shipboard archive-half measurements (Figs. 2, 3). The peaks labeled Exc correspond to intervals of anomalous inclination and declination values; (i.e., possible polarity excursions). The upper excursion interval at $\sim 25 \mathrm{~m}$ below seafloor (mbsf) was detected aboard ship during archive-half measuring and was selected for detailed sampling from the corresponding working-half core. Discrete sample analysis confirmed a simultaneous rise in intensity and inclination (Fig. 4), similar to anomalous remanence intervals in eight other Leg 155 holes (Cisowski, 1995, table 1). The lower excursion at $\sim 27.5$ mbsf was identified during post-cruise analysis, and has not yet been sampled at high density. Measurements on the 6- $\mathrm{cm}^{3}$ samples indicate a declination shift to $180^{\circ}$ and an inclination shift to $-60^{\circ}$ for this lower interval. Figure 5 is an ARM vs. susceptibility plot for the Figure 1A samples.

Figure 6 shows the declination, inclination, and normalized intensity record derived from detailed sampling over an anomalous remanence zone in Core 155-930B-10H. For many samples from this hole, a persistent vertically downward drilling remanence was not entirely removed with $\mathrm{AF}$ demagnetization at $25 \mathrm{mT}$ and above. This is reflected in a progressive shallowing of inclinations (Fig. 7A, B). Because of this effect, the declination and inclination values were taken from the highest demagnetization levels that gave repeatable results. Synchronous inclination and normalized intensity spikes (A) are the most prominent features of the Core $155-930 \mathrm{~B}-10 \mathrm{H}$ record. Similar, although somewhat diminished, features occur in Core 155-932A-3H (Fig. 4). The overall pattern for the discrete samples is similar to the high resolution $(0.5-\mathrm{cm}$ sampling interval) archive-half record obtained from the shipboard pass-through magnetometer (Flood, Piper, Klaus, et al., 1995, "Site 930" chapter, fig. 18). Note that the discrete sample depths have been corrected for voids in the core, whereas the archive-half measurements are uncorrected, and that the archive-half features have a different labeling scheme. Unfortunately, this anomalous remanence zone occurred at the bottom of a core with only $67 \%$ recovery, and so unlike Hole 932A, a record of the onset of the excursion was not obtained. Figure 8 is the ARM vs. susceptibility plot for the Core 155-930B-10H samples. Figures 9A and B compare the VGP (virtual geomagnetic pole) path derived from the Core 155930B-10H field vector data to the paths of the $\sim 32 \mathrm{ka}$ Lake Mungo Excursion recorded in three sediment cores from the Gulf of Mexico (Freed and Healy, 1974).

Figure 10 shows the declination, inclination, and normalized intensity data for an interval of anomalous field behavior recorded in Core $155-946 \mathrm{~A}-15 \mathrm{H}$. This zone is associated with a carbonate-rich interval (dotted lines) that is believed to represent an oxygen isotope Stage 5 interglacial highstand (Flood, Piper, Klaus, et al., 1995, "Leg Synthesis," fig. 3). Declination and inclination values for this core were derived by origin-anchored line fitting through linear portions of the orthogonal component curves, which generally represented AF demagnetization levels of 25 to $45 \mathrm{mT}$ (Fig. 11A). Thermal demagnetization subsequent to the AF removal of the vertical drilling remanence resulted in unidirectional behavior (Fig. 11B) Figure 12 is the ARM vs. susceptibility curve for the Core 155-946A-15H samples, and Figure 13A is the VGP path derived from the field vector data. Figure 13B is the VGP plot from a Substage 5c interglacial interval in Hole 942C which also exhibits anomalous remanence directions.

\section{DISCUSSION}

The persistence of the distinctive archive-half intensity pattern in the Hole 932A discrete samples, even after normalization to ARM (Fig. 1A), suggests that changes in geomagnetic field intensity are reflected in the Amazon Fan cores. Furthermore, the Hole 932A paleointensity curve bears a strong resemblance to the Tric et al. (1992) late Pleistocene paleointensity curve derived from Mediterranean cores (Fig. 1B). This suggests that changes in dipole intensity are reflected in both records.

Normalized intensities for discrete samples from Hole 942A (4$15 \mathrm{mbsf}$ ) were also measured. Although the labeled intensity peaks from the archive-half measurements (Flood, Piper, Klaus, et al., 1995, "Site 942" chapter, fig. 19) are still identifiable in the normalized intensity curves, they are not as prominent as the Hole 932A features. Also, the intensity low L1 was obscured because it fell in a sandy interval. The discrete samples from this interval fall far off the linear ARM vs. susceptibility curve defined by the higher samples, indicating the dominance by coarse multidomain remanence carriers (King et al., 1982). Overall, samples from Site 942 west of the fan appear to be less amenable to relative paleointensity estimates than the higher accumulation rate Site 932 sediments from the Amazon Fan proper.

Table 1 presents a revised identification of the archive-half intensity features for a number of Leg 155 holes. This reevaluation differs in part from the shipboard correlation (Cisowski, 1995, table 2) as only holes with the best defined intensity patterns were retained. Also additional features F-J and L2 dating from $\sim 43$ to 80 ka have been included. The correlation in intensity patterns between holes is now also in general agreement with the channel-levee age stratigraphy, as determined by core-seismic integration. Age assignments for intensity peaks A-J and lows L1 and L2 have been made by identifying similar features (Fig. 1B) in the dated Mediterranean paleointensity curve (Tric et al., 1992).

The two excursions identified in Figure 1A correspond to ages of $\sim 30-35 \mathrm{ka}$ and $\sim 40-45 \mathrm{ka}$, based on the comparison to the Tric et al. (1992) paleointensity curve (Fig. 1B). The older excursion most likely represents the Laschamp Excursion ( 43 ka), which has been identified primarily from lava flows (Thouveny and Creer, 1992) and is known to occur within the pronounced dipole intensity low centered on $\sim 40 \mathrm{ka}$ (Valet and Meynadier, 1993). The younger excursion might correspond to the Lake Mungo Excursion ( $32 \mathrm{ka}$, based on average ages of $30.4 \mathrm{ka}$ from ${ }^{14} \mathrm{C}$ dating and $33.5 \mathrm{ka}$ from thermoluminescent dating-Huxtable and Aitken, 1977), which was first identified in early hominid fireplaces in southeast Australia (Barbetti and McElhinny, 1976). The prominent, sharp, synchronous rise in inclination and normalized intensity peaks occurs within a broader zone of anomalous westward declinations in the Leg 155 cores (Figs. $4,6)$. This similar remanence character allowed for the identification of potential analogues to this excursion in Hole 930C (Flood, Piper, Klaus, et al., 1995, "Site 930" chapter, fig. 15) and in six additional holes from five other sites (Cisowski, 1995, table 1). The repeated occurrence of these excursions at about two-thirds the depth of the 40 k.y. P. obliquiloculata paleontological datum (Flood, Piper, Klaus, et al., 1995, "Leg Synthesis," fig. 3), also led to a shipboard age assignment of $\sim 30$ k.y., and an association with the Lake Mungo Excursion (note that the $\sim 10 \mathrm{k} . \mathrm{y}$. of Holocene time at each Leg 155 site is represented by $>1 \mathrm{~m}$ of sediment at the top of each hole). Preliminary ${ }^{14} \mathrm{C}$ 

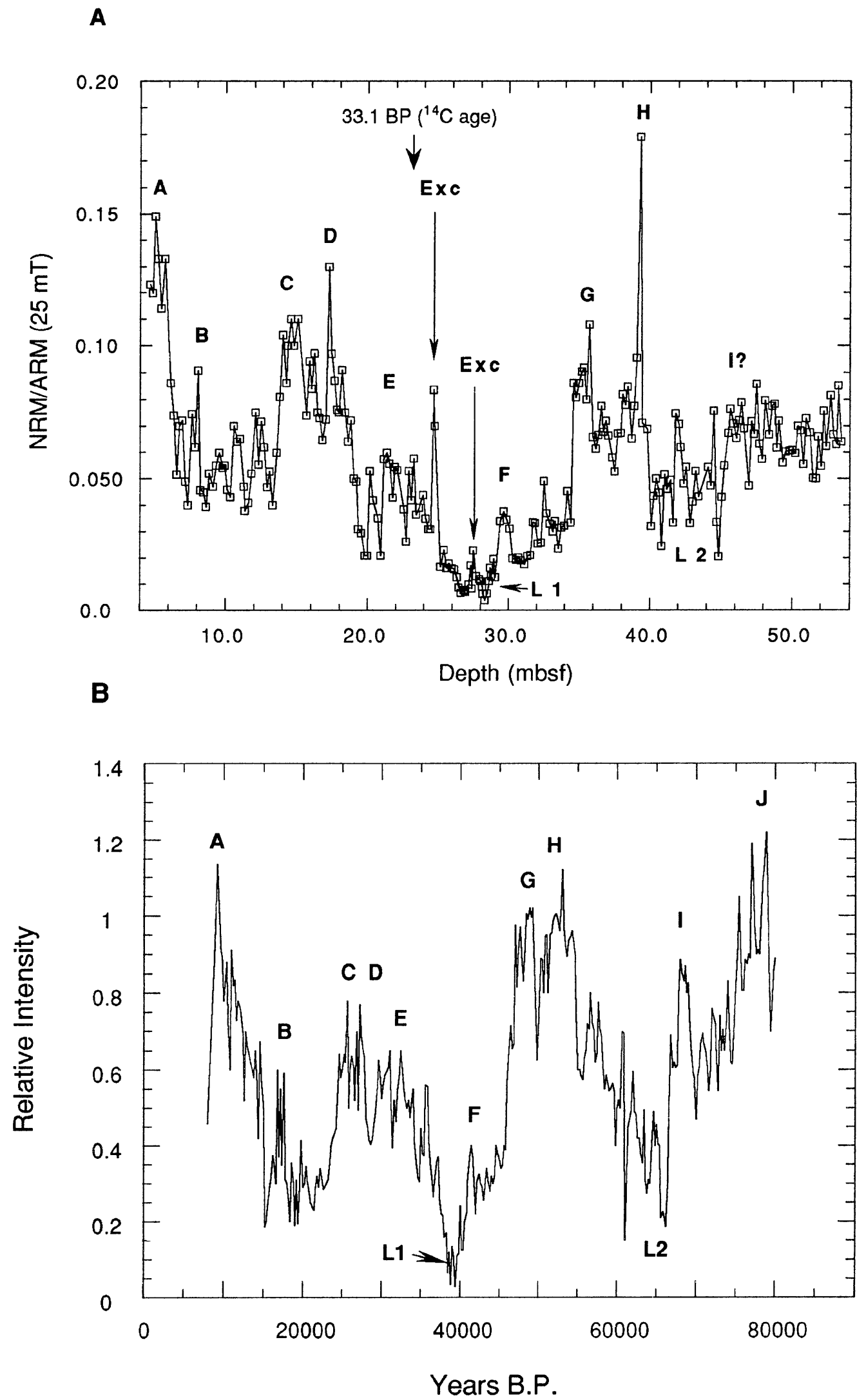

Figure 1. A. Normalized remanence intensity (after AF demagnetization to $25 \mathrm{mT}$ ) vs. depth for discrete samples from the interval 4-54 mbsf in Hole $932 \mathrm{~A}$. Intensity peaks A-I and intensity lows L1 and L2 correspond to similar features measured on the corresponding archive-half core sections. Two intensity peaks labeled Exc are zones of anomalous inclination and declination that imply the movement of the VGP to low latitudes (i.e., excursions). Depths have been corrected for voids in the core. B. Relative paleointensity curve derived by Tric et al. (1992) from Mediterranean Sea cores. Correlated intensity features are labeled. 
A

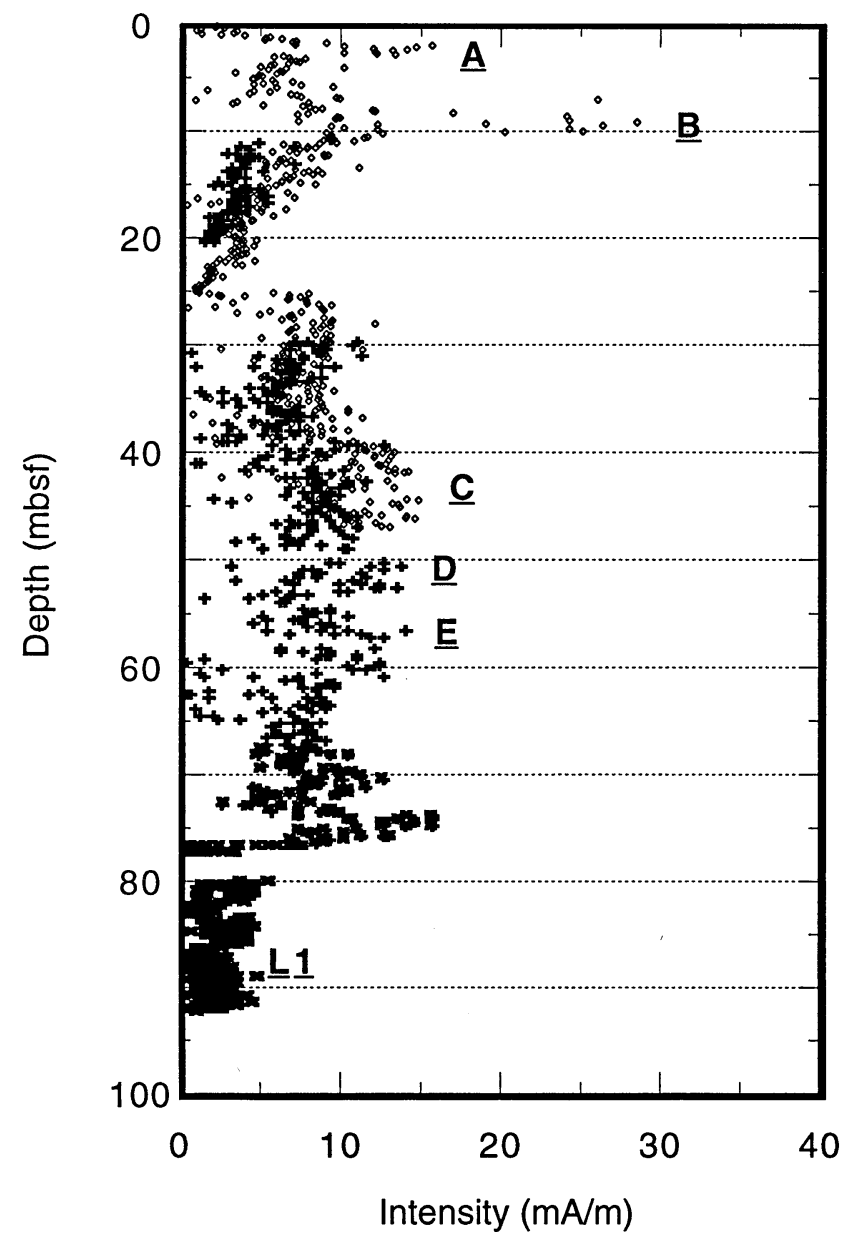

B

Hole 933A

Figure 2. Shipboard intensity measurements on archive-half core sections for intervals of (A) Holes 931A, 931B, and 931C and (B) Hole 933A. Intensity features have been labeled as in Figure 1.

dating of a Sample 155-932A-3H-6, 20-24 (23.20 mbsf), taken 1.5 $\mathrm{m}$ above the inclination and intensity peaks, indicates an age of 32.7 ka (M. Maslin, pers. comm., 1995).

In the plot of ARM vs. susceptibility for Hole 930B samples in Figure 8, 10 samples (eight between 85.5 and $86.15 \mathrm{mbsf}$ ) fall well above the linear trend (dashed line) defined by the other samples. Linearity on the ARM vs. susceptibility plot is a generally accepted criterion for the acceptance of normalized intensity data as a relative paleointensity indicator (King et al., 1983). The higher ARM to susceptibility ratios of these samples indicates a predominance of finer grain sizes within the magnetic fraction. However, the Figure 8 insert plot shows that the NRM to ARM ratios of these samples fall near the center of the range of the other samples, but no significant correlation exists between normalized intensity and ARM intensity. Therefore, the overall normalized remanence record in Figure 6 is likely to represent a credible analogue of intensity changes associated with the geomagnetic excursion.

The VGP path for the Core 155-30B-10H excursion shows a preponderance of near equatorial poles in the eastern Pacific, with a rapid swing toward Central America (A in Fig. 9A). This eastward swing corresponds to the relative intensity high centered on 86 mbsf in Figure 6. This path is similar to the $\sim 32 \mathrm{ka}$ Gulf of Mexico excursion (Fig. 9B) identified by Freed and Healy (1974) as the Lake Mungo Excursion. VGPs derived from two of the Lake Mungo hearths (LM in Fig. 9B) fall along the Hole 930B eastward swing path. Heating experiments (Thellier and Thellier, 1959) on one of these hearths (VGP at $238^{\circ} \mathrm{E}, 8^{\circ} \mathrm{S}$ ) gave paleointensity values $\sim 3 \times$ the present field at their site, and $\sim 5 \times$ the background field strength outside the excursion (Barbetti and McElhinny, 1976). Normalized intensity results were not reported for the Gulf of Mexico excursion, although Freed and Healy (1974) state that no significant decrease in remanence intensity is associated with their excursion.

The Core 155-946A-15H interglacial Stage 5 record displays several intervals of an $\sim 180^{\circ}$ declination anomaly labeled (A-D in Fig. 10 ), which corresponds to periods of near-reversed polarity in the VGP plot (Fig. 13A). Figures 11A and B show the response of individual discrete samples from these zones to $\mathrm{AF}$ and continuous thermal demagnetization. This result contrasts with the Core 155-930B$10 \mathrm{H}$ record, where nearly all of the excursion poles occupy low latitudes, with only a single pole at a high southern latitude (B in Fig. 9A). Therefore the Hole 946A record represents a geomagnetic polarity event, in contrast to the more limited excursion record of Hole 930B. The Hole 946A record also contrasts with another partial excursion record (a zone of no recovery immediately overlying the anomalous remanence interval) obtained from discrete samples from another interglacial interval in Core 155-942C-3H (Fig. 13B). In this core, samples with anomalous remanence directions spanned a depth interval of $2.3 \mathrm{~m}$. Foraminifer oxygen isotope studies on Hole 942A 
A

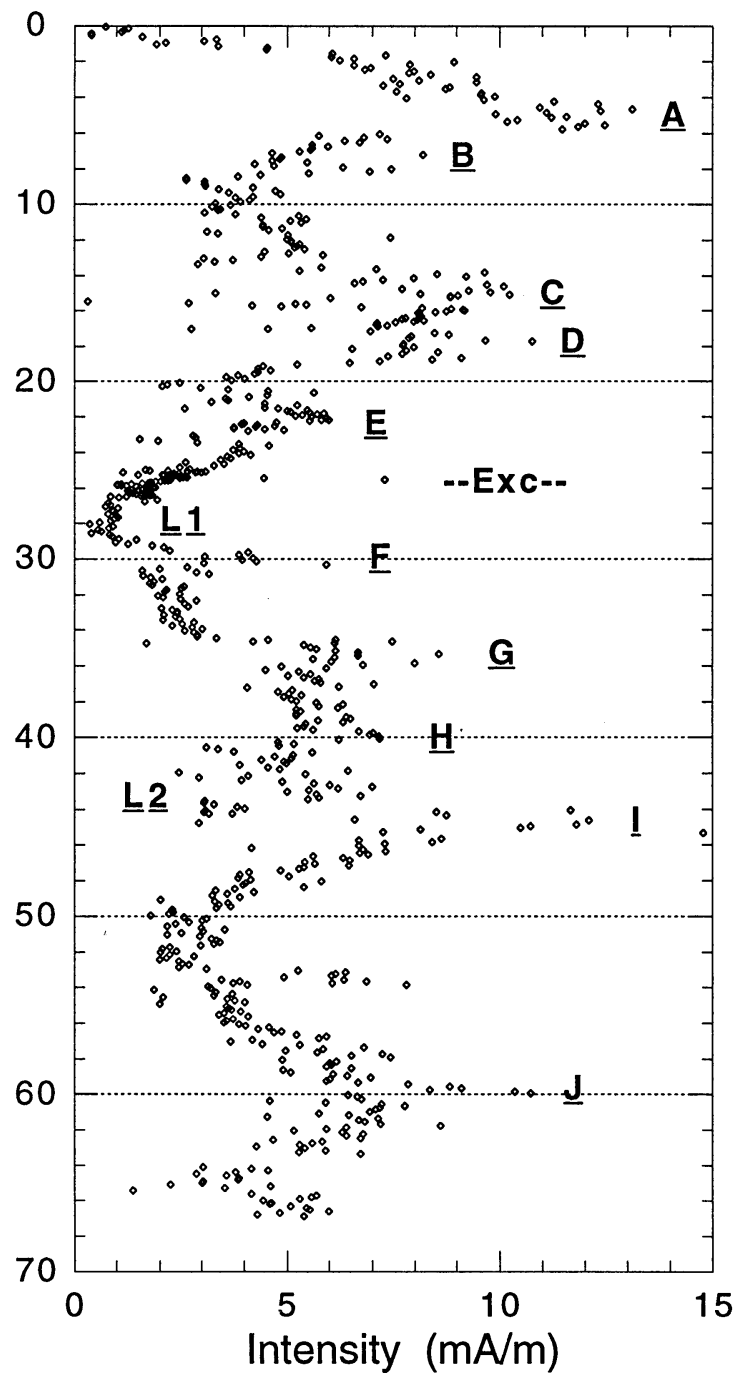

B Hole $942 \mathrm{~A}$

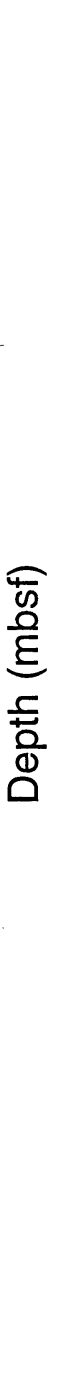

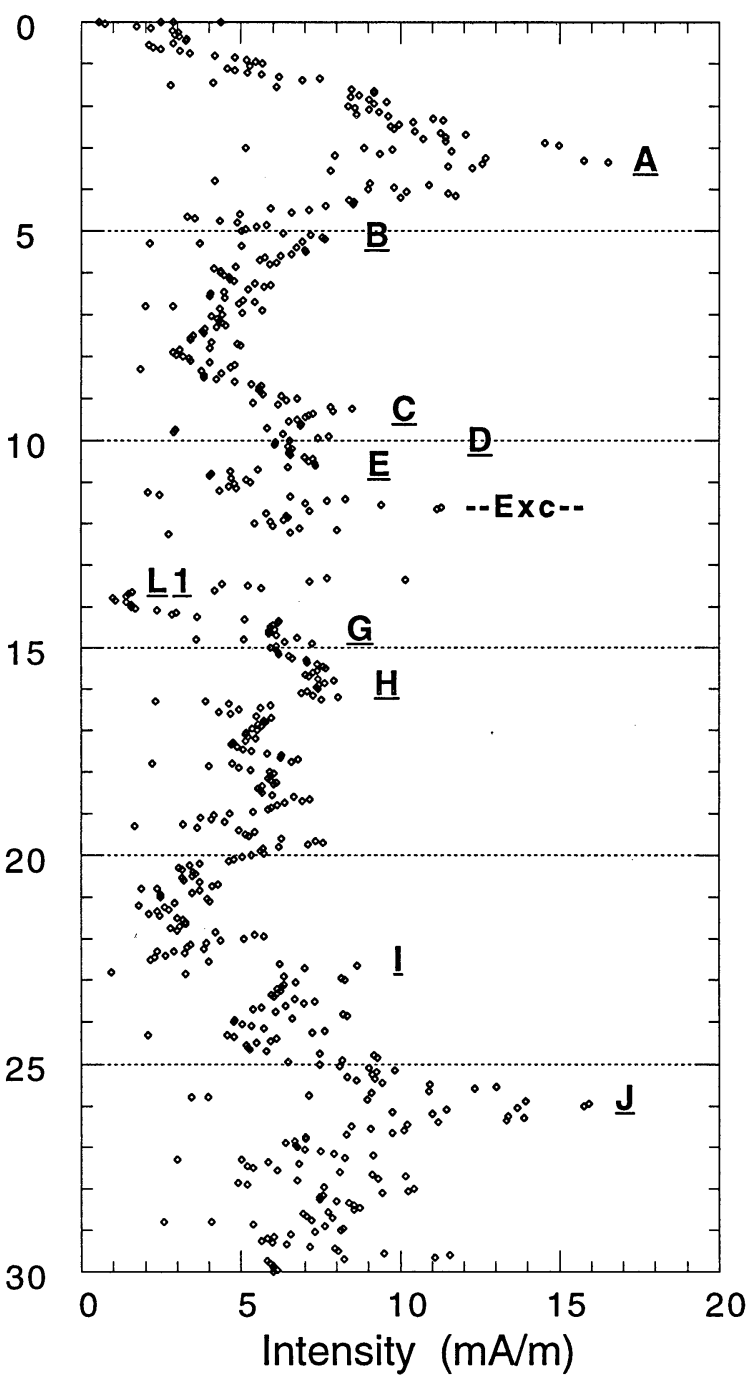

Figure 3. Shipboard intensity measurements on archive-half core sections for the upper parts of (A) Hole 932A and (B) Hole 942A. Intensity features have been labeled as in Figure 1.

indicate that the carbonate interval associated with this latter excursion represents Substage 5c at $\sim 97 \mathrm{ka}$ (Showers et al., this volume). The sedimentation rates for the Leg 155 interglacial carbonate-rich clays are estimated at $\sim 0.1 \mathrm{~m} / \mathrm{k} . \mathrm{y}$. (Flood, Piper, Klaus, et al., 1995).

Although incomplete, the Core 155-942C-3H VGP path clearly represents a separate geomagnetic excursion, implying that the interglacial carbonate interval in Core $155-946 \mathrm{~A}-15 \mathrm{H}$ is not Substage 5c. Henyey et al. (1995) have identified a Blake Event in sediments from the Blake/Bahama Outer Ridge, which includes reversed VGPs, associated with early Substage 5e. Our Hole 942C excursion may instead be associated with a broad intensity low and a Blake Event in sediments from the Mediterranean (Tric et al., 1991, figs. 8, 10a), which has been associated with the Substage $5 \mathrm{~d} / 5 \mathrm{e}$ boundary (Tucholka et al., 1987).

The ARM vs. susceptibility plot for the Core 155-946A-15H samples (Fig. 12) is far from linear, with samples from near the upper part of the carbonate-rich layer (6.5\% to $35.5 \%$ carbonate) exhibiting diamagnetic (negative) susceptibilities. The inset diagram shows that although the diamagnetic samples all have low normalized intensity ratios, a number of samples with higher positive susceptibilities have comparably low normalized intensities. The inference is that the normalized intensity low that is associated with the anomalous remanence directions and the carbonate zone (Fig. 10) reflects to a large extent a diminished paleofield.

A comparison of the Core 155-930B-10H excursion (Fig. 6) and the Core 946A-15H event (Fig. 10) reveals a number of contrasts in addition to the range of VGP motion. Although the excursion is characterized by variable normalized intensities with minimum values no less than half the post-excursion values, the event is associated with intensities an order of magnitude lower than pre-event values. Furthermore, the intensity peak at 86 mbsf in the excursion record is most unusual, not only because it suggests a paleointensity value in excess of the post-excursion background field, but also because of its extremely short duration. With an estimated accumulation rate of 5.4 $\mathrm{m} / \mathrm{k} . \mathrm{y}$., the intensity peak and associated movement of the VGP over $60^{\circ}$ of longitude would have occurred over a period of less than 40 years!

Because we were concerned that the synchronous peaks in intensity and inclination could possibly be artifacts of incomplete removal of a drilling overprint, we performed a number of additional experi- 


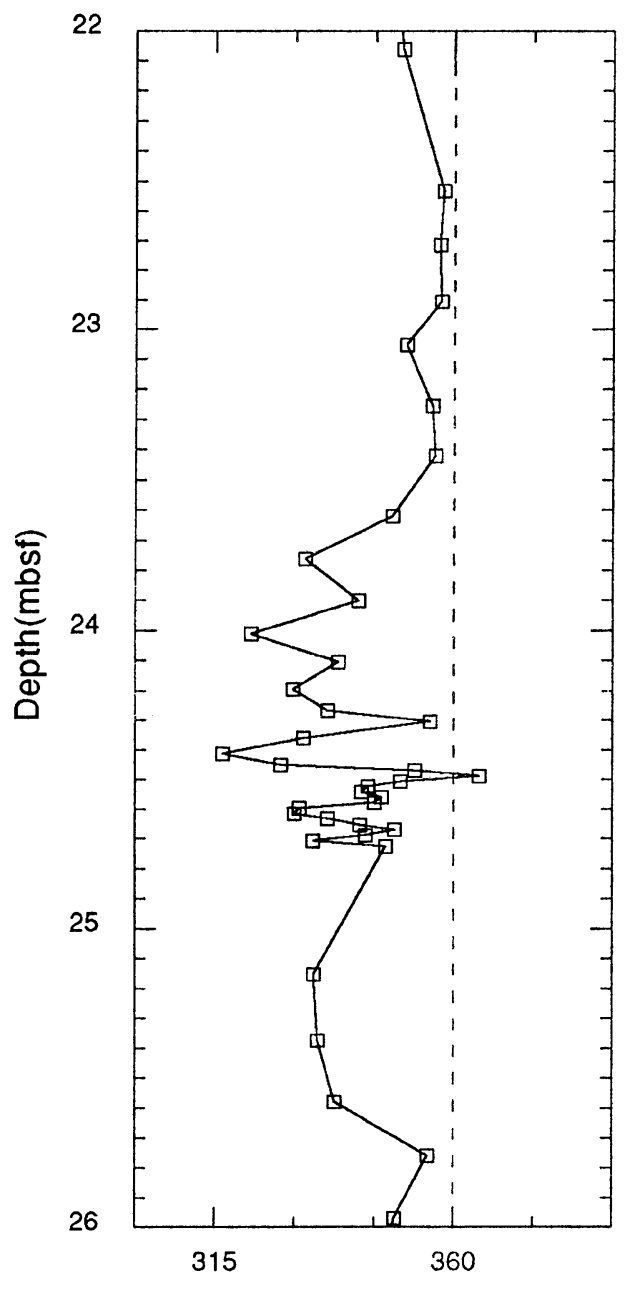

declination (degrees)
22

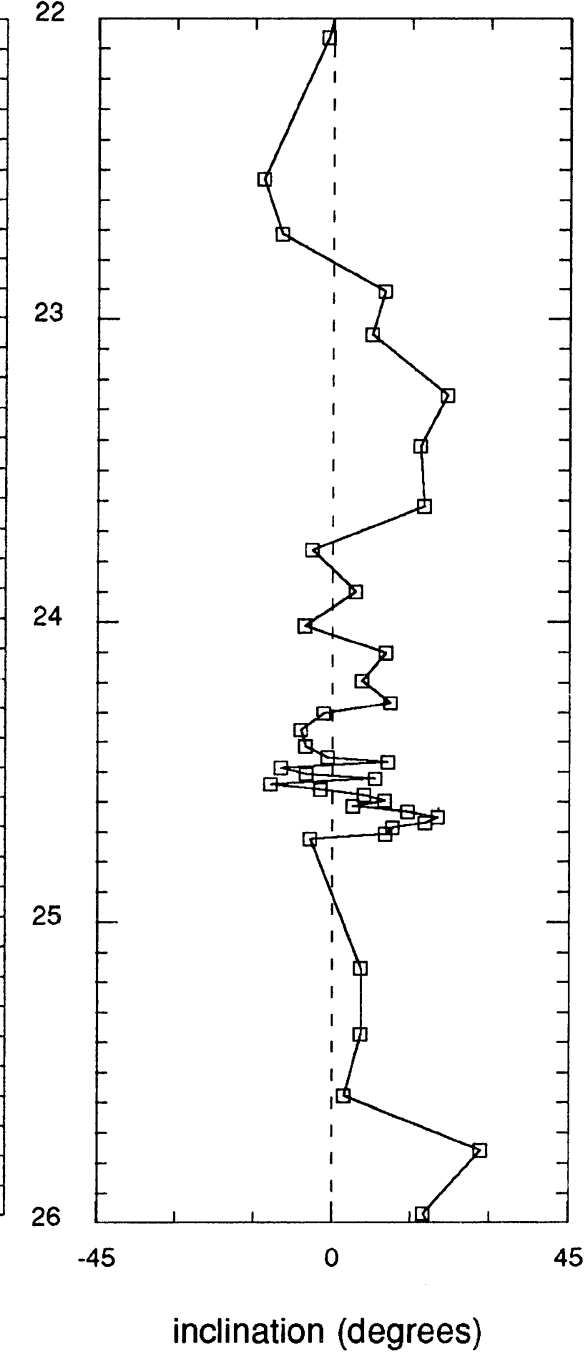

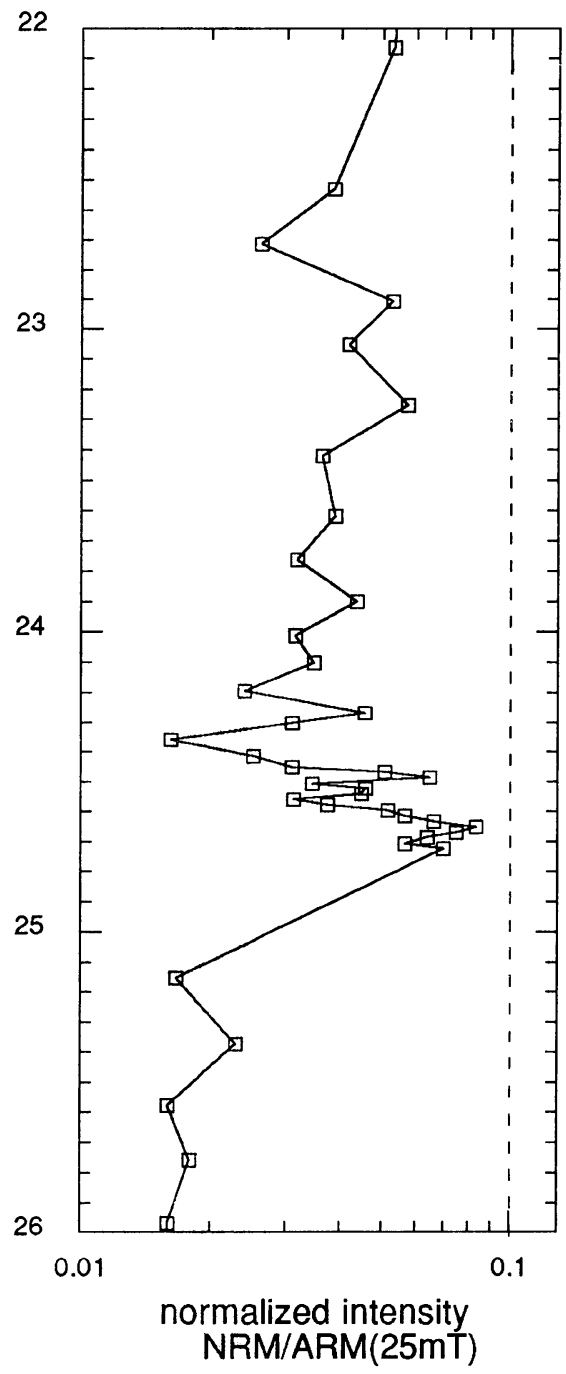

Figure 4. Discrete sample declination, inclination, and normalized intensity vs. depth for the upper excursion interval at $\sim 25 \mathrm{mbsf}$ in Hole $932 \mathrm{~A}$ (Fig. $1 \mathrm{~A}$ ). Depths have been corrected for voids in the core. The declinations were derived via azimuthal orientation with a downhole vector tool.

Table 1. Correlation of Leg 155 intensity features.

\begin{tabular}{lcccccc}
\hline \multirow{2}{*}{$\begin{array}{l}\text { Intensity } \\
\text { features }\end{array}$} & Levee systems & \multirow{2}{*}{$\begin{array}{c}\text { Age } \\
\text { (ka) }\end{array}$} & & \multicolumn{5}{c}{ Hole depth (mbsf) } \\
\cline { 5 - 7 } & & & $931 \mathrm{~B}$ & $932 \mathrm{~A}$ & $933 \mathrm{~A}$ & $942 \mathrm{~A}$ \\
\hline Peak A (\#1) & Amazon & 9 & 2 & $5^{*}$ & 3 & $3^{*}$ \\
Peak B (\#3) & Brown/Aqua & 17 & 10 & $8^{*}$ & $12 ?$ & $5^{*}$ \\
Peak C & Yellow & 26 & 45 & $15^{*}$ & 26 & $9^{*}$ \\
Peak D & Yellow & 27 & 52 & $18^{*}$ & $35 ?$ & $10^{*}$ \\
Peak E & Yellow & 30 & 57 & $22^{*}$ & $46 ?$ & $10.5^{*}$ \\
Low L1 & Channel 5 & $\sim 39$ & $80-92$ & $22^{*}-28^{*}$ & $84-89$ & $\sim 14$ \\
Peak F & & 42.5 & - & $30^{*}$ & - & - \\
Peak G & & 49 & - & $35^{*}$ & - & 14.5 \\
Peak H & & 54 & - & $40^{*}$ & - & 16 \\
Low L2 & & 66 & - & $41^{*}-44^{*}$ & - & 22.5 \\
Peak I & & 68 & - & $45^{*}$ & - & 23 \\
Peak J & & 76 & - & 60 & - & 26 \\
\hline
\end{tabular}

Notes: $*$ features that were confirmed by normalized intensity measurements on discrete samples. Peaks A and B correspond to Peaks \#1 and \#3 of Amazon to Aqua intervals (Cisowski, 1995, table 2). Ages are by comparison to the relative paleointensity curves of Tric et al. (1992) from the Mediterranean Sea (Fig. 1B). ments on the samples from this interval. Figure 14 contrasts the coercivity spectra, as delineated by high field isothermal remanent magnetization (IRM) acquisition and AF demagnetization curves, of the sample from the center of the peak (solid line) to low normalized intensity samples from above and below. The demagnetization curves in particular are nearly identical. Likewise, the samples defining the peak display a broad range of ARM to susceptibility ratios. Figure 6 (solid squares) shows the results of remanence normalization at a higher (35 mT) AF field. Although the sample at the center of the peak shows a moderate decline in its remanence ratio, the overall integrity of the peak is maintained. ARM measurements made on these same samples after several days of storage showed no decline in intensity as compared to initial measurements made immediately after acquisition, indicating a lack of viscous behavior for samples associated with the peak. Furthermore, continuous thermal demagnetization of Sample 155-930B-10H-4, 35-36 cm, from the lower part of the feature shows that a high inclination is maintained to $\sim 590^{\circ} \mathrm{C}$, although progressive shallowing of inclination occurs to that point.

The lower sedimentation rate within Hole 932A ( 1.2 m/k.y.) may account for the diminished directional and intensity anomaly in Core 155-932A-3H (Fig. 4), when compared to the Core 155-930B$10 \mathrm{H}$ excursion record (Fig. 6). Thouveny and Creer (1992) have demonstrated that decreasing sedimentation rates will substantially di- 


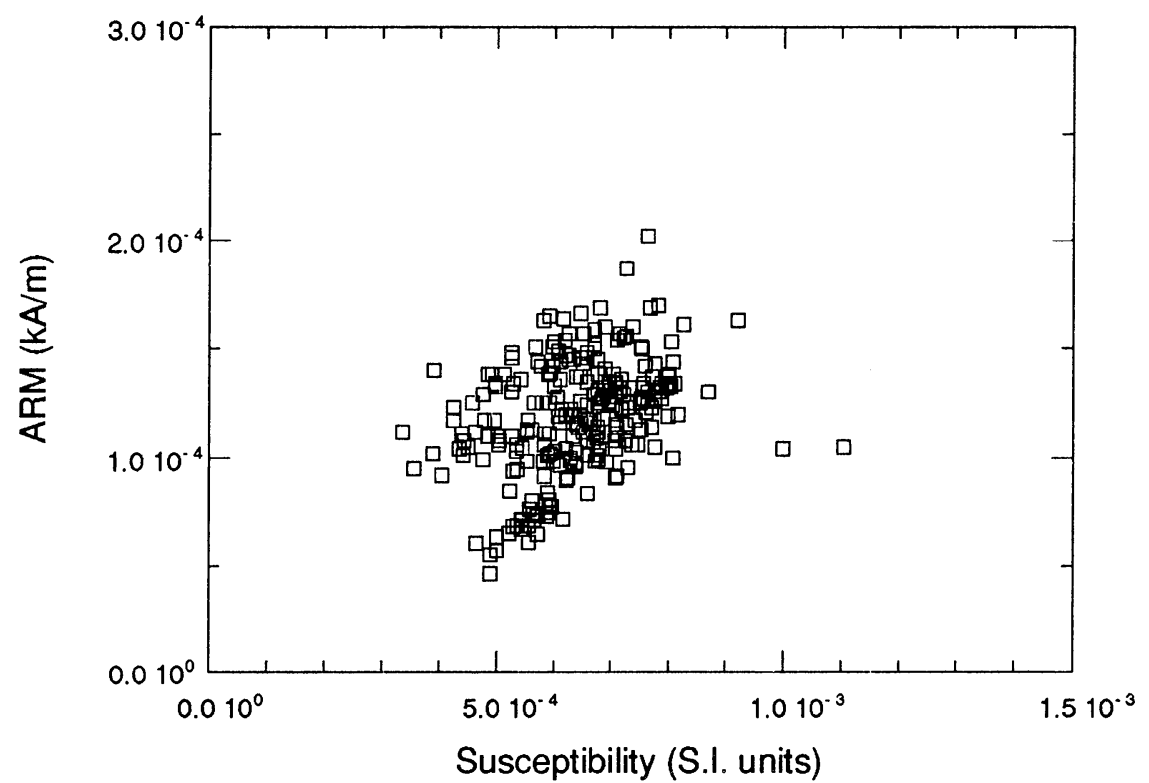

Figure 5. ARM intensity vs. susceptibility plot for Hole 932A samples included in Figure 1A. ARM values are after AF demagnetization to $25 \mathrm{mT}$.
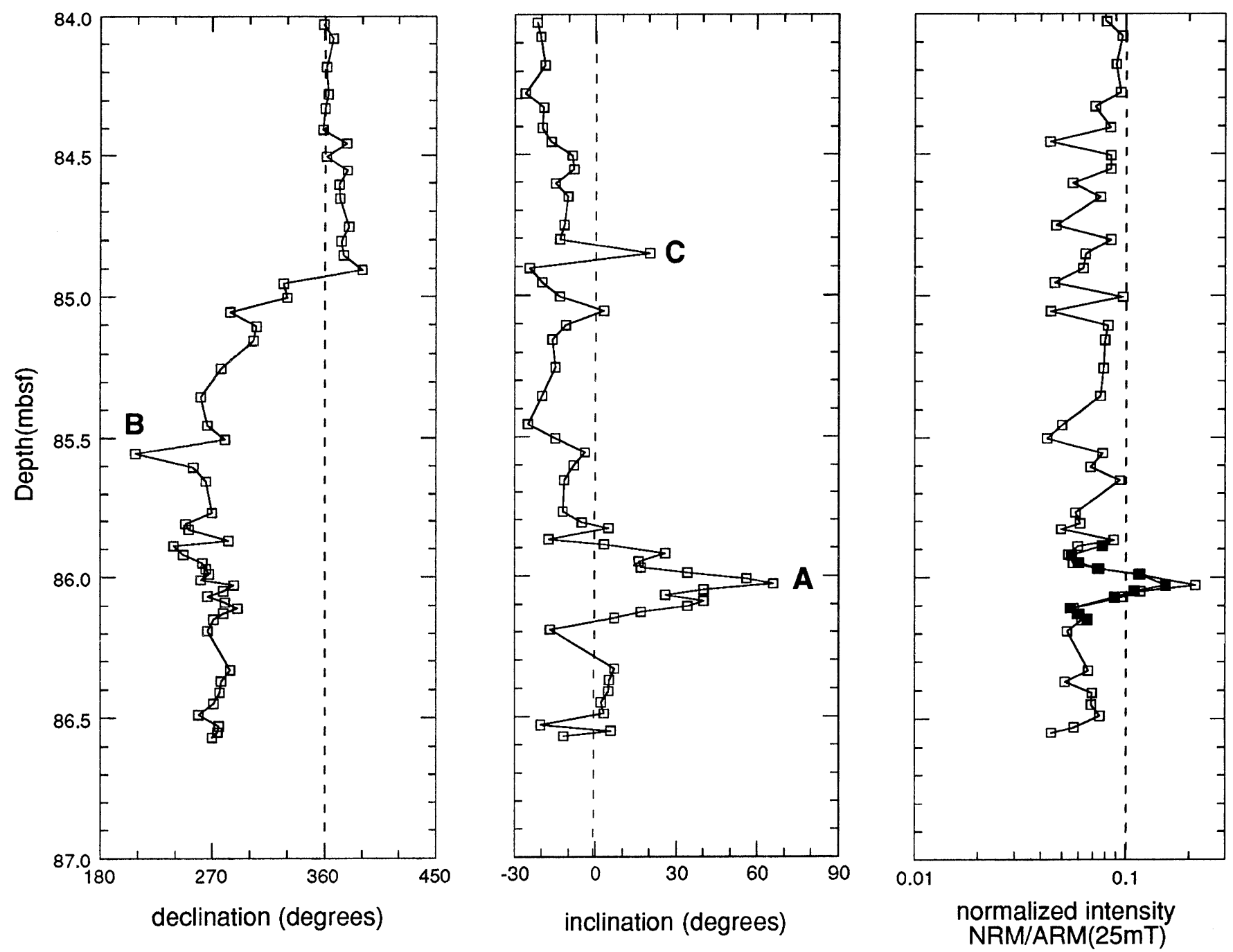

Figure 6. Discrete sample declination, inclination, and normalized intensity vs. depth for the late Pleistocene excursion recorded in the bottom part of Core 155930B-10H. Open squares represent normalized intensities after AF demagnetization to $25 \mathrm{mT}$, solid squares to $35 \mathrm{mT}$. Prominent short-lived features are labeled A, B, and C. Depths have been corrected for voids in the core. The declinations were derived via azimuthal orientation with a downhole vector tool. The estimated accumulation rate is $5.4 \mathrm{~m} / \mathrm{k} . \mathrm{y}$. 
A

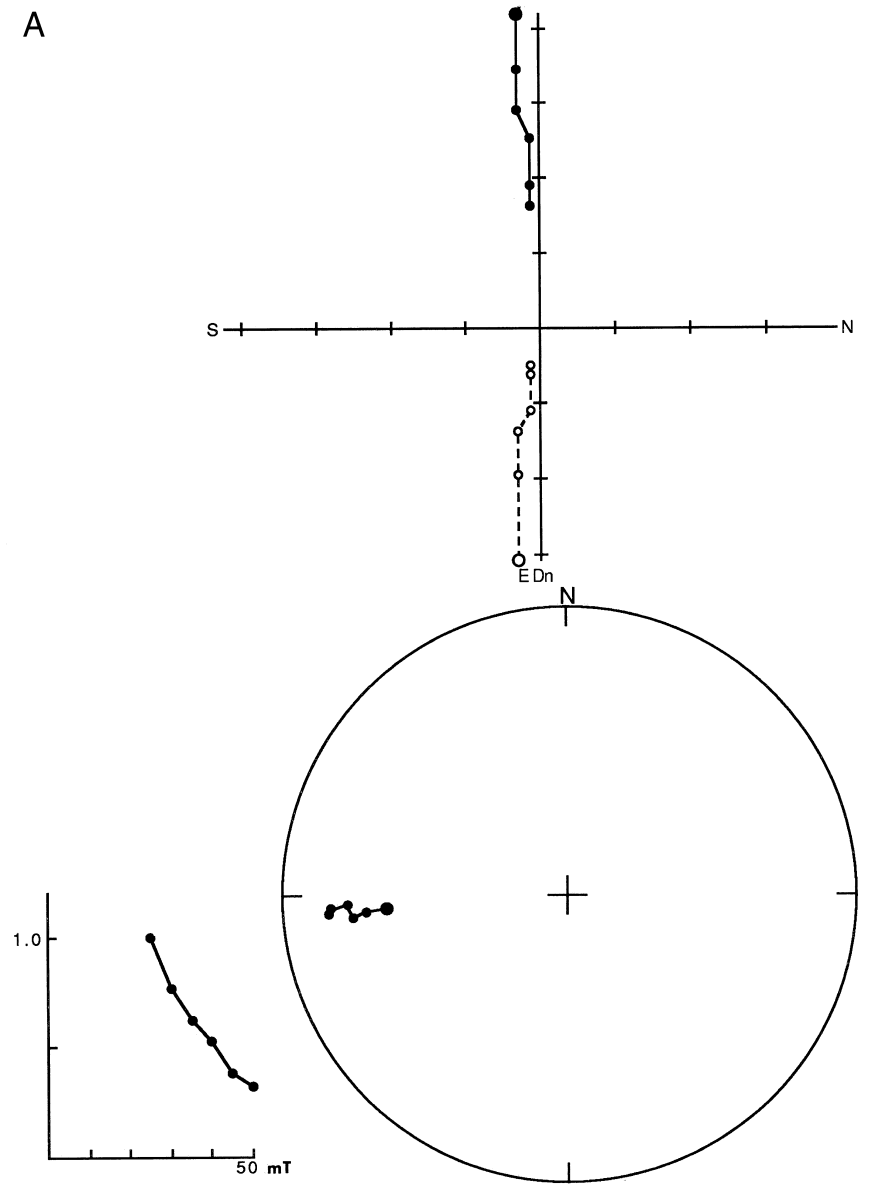

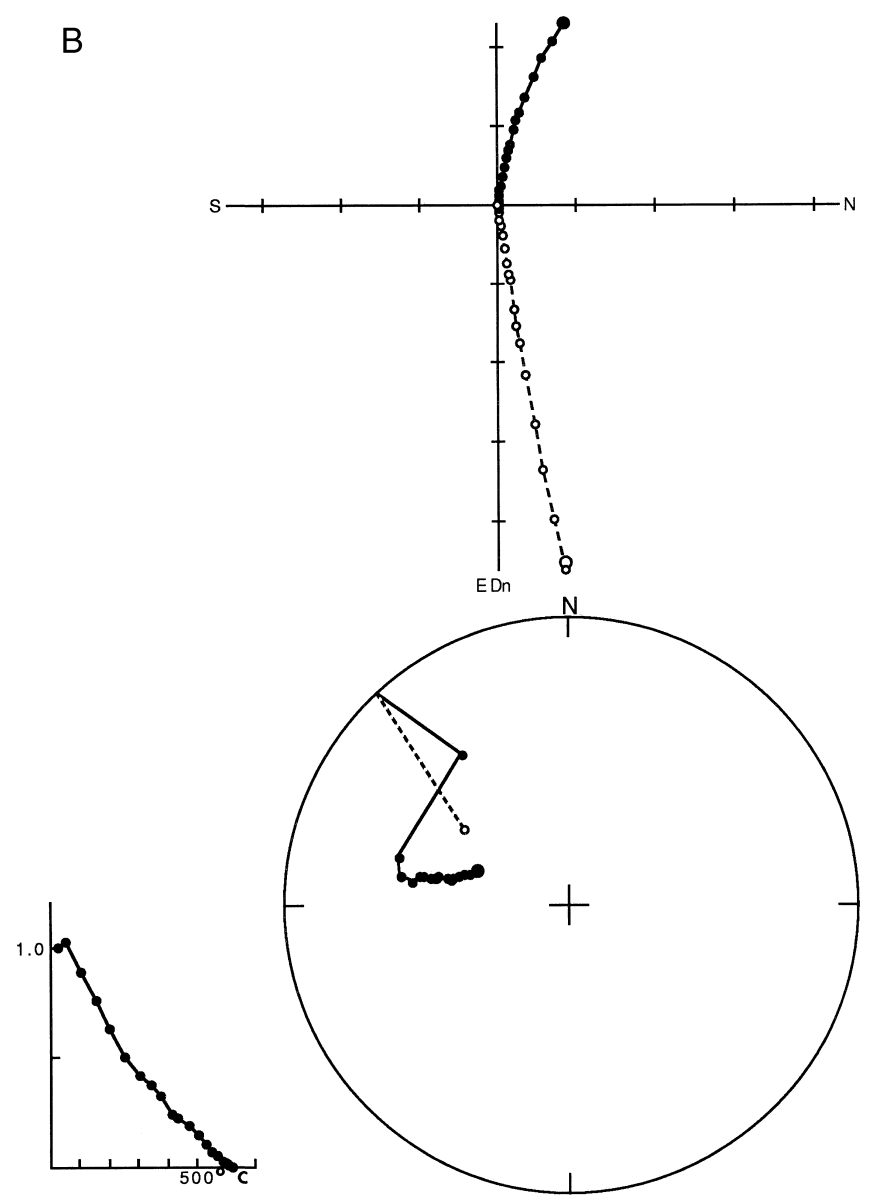

Figure 7. Variation of orthogonal components, normalized intensities, and field vector directions, with demagnetization, for (A) excursion Sample 155-930B$10 \mathrm{H}-4,23-24 \mathrm{~cm}$ (25 to $50 \mathrm{mT}$ AF) and (B) excursion Sample 155-930B-10H-4, 35-36 cm (continuous thermal).

minish the extent of an excursion signal due to "locking-in depth" smoothing. The extremely short-lived Lake Mungo intensity peak would not be expected to be resolved in sediments with more typical (>1 m/k.y.) sedimentation rates, such as the Freed and Healy (1974) Gulf of Mexico cores.

We face a paradoxical situation in interpreting the significance of the $\sim 32$ ka excursion record, particularly in reference to the extremely brief intensity rise. The correspondence of our VGP path to the Gulf of Mexico excursion record and to two of the Lake Mungo hearth poles, along with the high paleointensities associated with a number of the Lake Mungo sites, suggests highly anomalous dipole behavior. In fact, Freed and Healy (1974) suggested that this excursion may have been the result of dipole tilt rather than dipole decay. This conclusion would also be consistent with our overall normalized intensity results across the excursion interval (Figs. 4, 6). However, the apparently brief timespan $(<50 \mathrm{yr})$ of the intensity and inclination change at $\sim 86$ mbsf would seem to belie a dipole association.

Another indication that the $\sim 32$ ka excursion may represent an unusual and perhaps unique geomagnetic event comes from the detection of a ${ }^{10} \mathrm{Be}$ spike at approximately this time (McHargue et al., 1995). This cosmogenic isotope anomaly differs from another ${ }^{10} \mathrm{Be}$ spike associated with the Laschamp Excursion, because, although shorter-lived, it is more than twice as intense, and also because of its apparent global extent, as it has been detected in both the Gulf of California and in Antarctic ice cores (Sonett et al., 1987). It cannot be explained in terms of a decrease in dipole field strength, as can ${ }^{10} \mathrm{Be}$ anomalies associated with the paleointensity lows at $\sim 40 \mathrm{ka}$ and $\sim 65$ $\mathrm{ka}$, and the Matuyama/Brunhes polarity reversal (Raisbeck et al., 1985). While McHargue et al. (1995) relate the $\sim 33$ and $\sim 43 \mathrm{ka}{ }^{10} \mathrm{Be}$ anomalies and associated excursions to a postulated nearby supernova event, they do not present a mechanism whereby such an extrasolar event can have a profound effect on the geomagnetic field.

\section{SUMMARY}

A comparison of normalized remanence results from Hole 932A to relative paleointensity curves derived from Mediterranean sediment cores indicates that the recurring remanence intensity patterns at a number of Leg 155 sites reflect changes in the geomagnetic dipole strength for the period of 8-80 ka. Two intervals of anomalous remanence directions from this time are recorded in the Amazon Fan sediments and appear to correspond to the Lake Mungo ( $32 \mathrm{ka})$ and Laschamp ( $\sim 3 \mathrm{ka}$ ) Excursions. An older excursion associated with interglacial Substage 5c ( $97 \mathrm{ka})$ and a geomagnetic event possibly associated with the Blake Event in Substage 5e ( 122 ka) also have been identified through discrete sample analysis of Leg 155 cores.

A prominent feature of the $\sim 32$ ka excursion is a short-lived $(\sim 40$ yr) synchronous peak in relative intensity and inclination. The extreme brevity of this and other directional features associated with this excursion is difficult to reconcile with a suggested dipolar nature for this atypical excursion. 


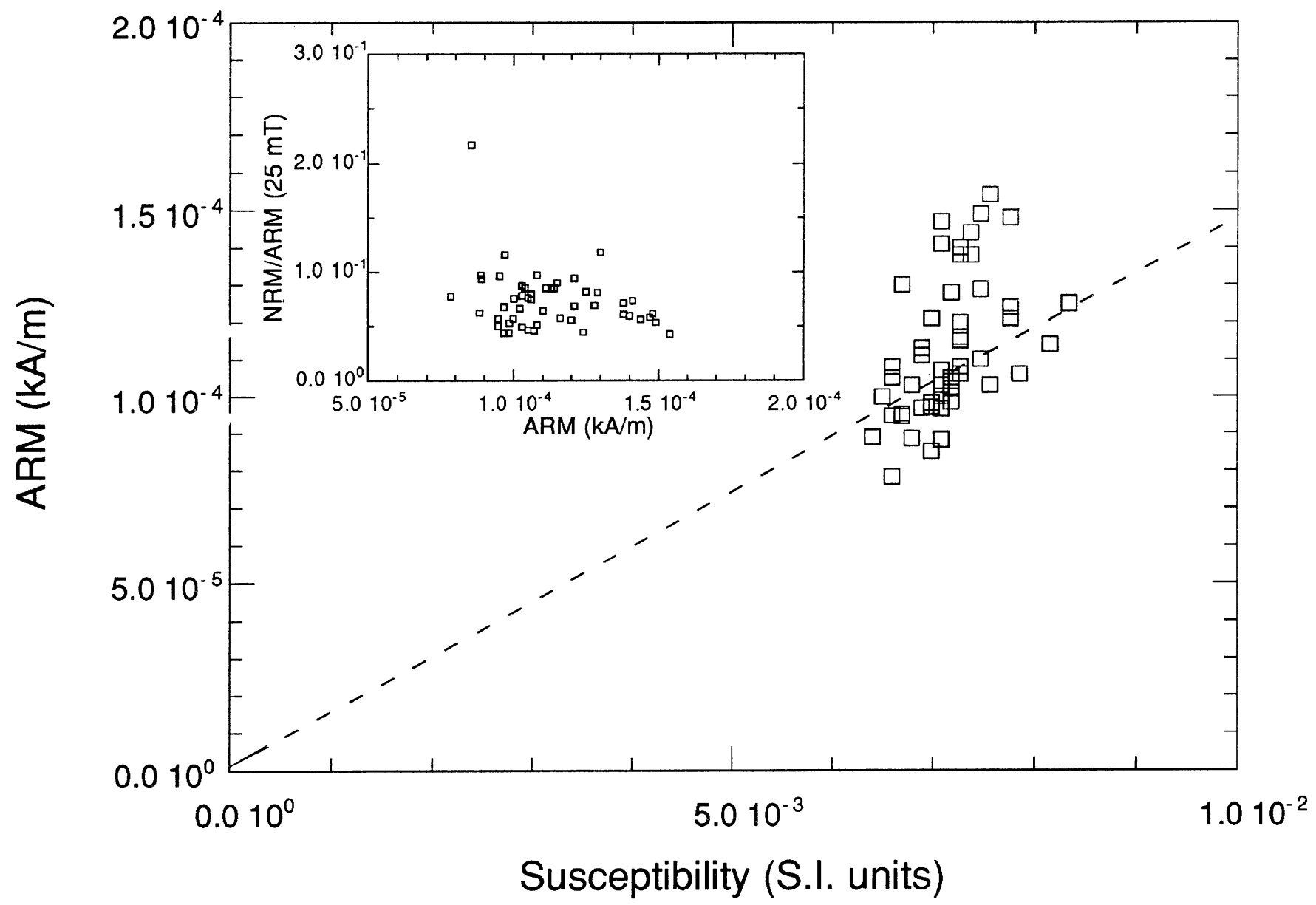

Figure 8. ARM intensity vs. susceptibility plot for Core 155-930B-10H samples included in Figure 6. Inset shows the variation of normalized remanence intensity with ARM intensity, after demagnetization to $25 \mathrm{mT}$.
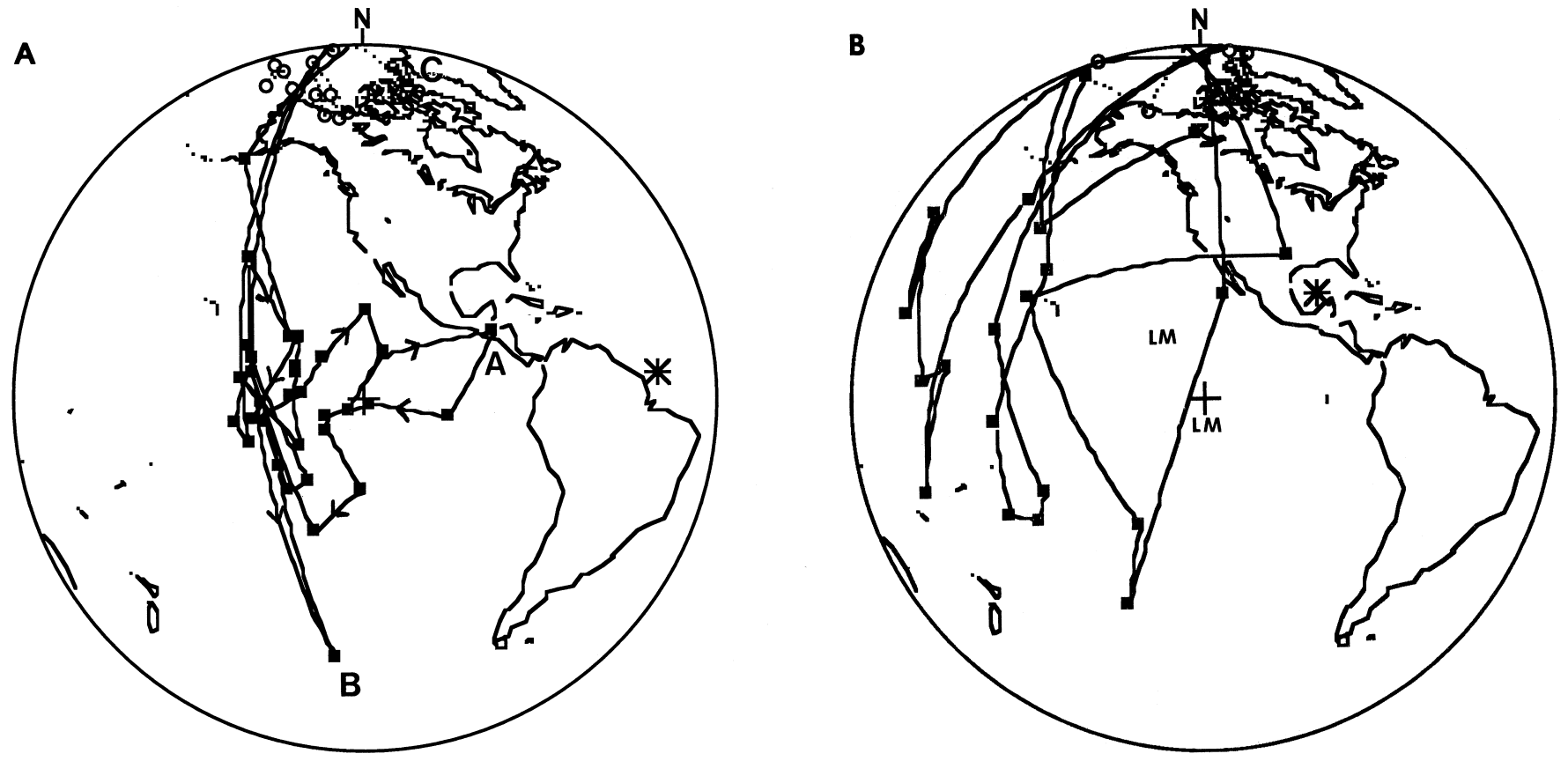

Figure 9. A. VGP path for the excursion recorded in Core 155-930B-10H. A, B, and C correspond to features in Fig. 6. B. VGP paths reported by Freed and Healy (1974) for an $\sim 32 \mathrm{ka}$ excursion recorded in three sedimentary cores from the Gulf of Mexico (sedimentation rate of $\sim 0.15 \mathrm{~m} / \mathrm{k}$.y.). LM denotes VGP derived from $\sim 32 \mathrm{ka}$ aboriginal firepits at Lake Mungo, Australia (Barbetti and McElhinny, 1976). Asterisks denote drilling site locations. 

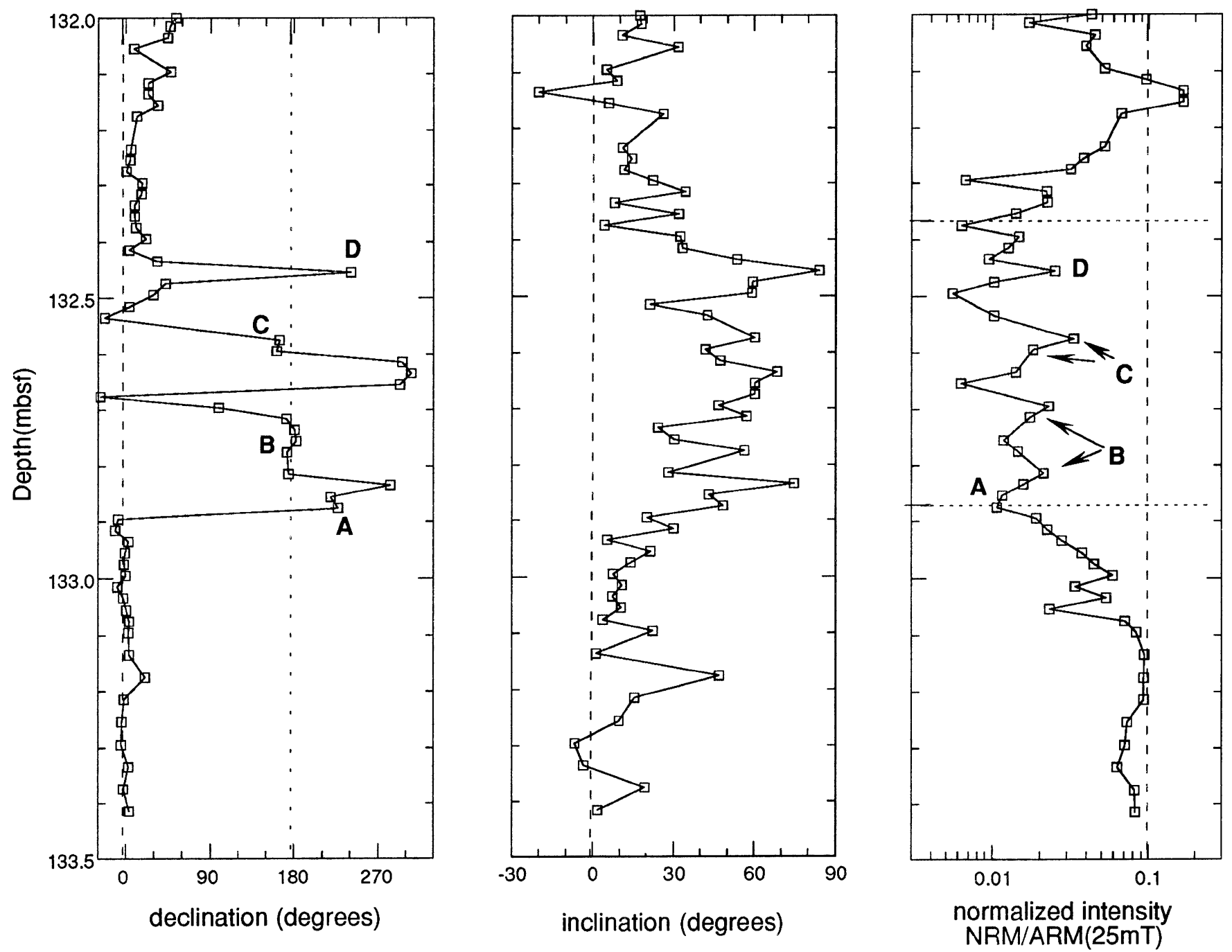

Figure 10. Discrete sample declination, inclination, and normalized intensity data vs. depth for an apparent geomagnetic event recorded in interglacial Stage 5 sediments from Core 155-946A-15H. Prominent shifts in declination are labeled A, B, C, and D. Horizontal dotted lines indicate the upper and lower boundaries of an associated carbonate-rich zone (sedimentation rate $\sim 0.1 \mathrm{~m} / \mathrm{k} . \mathrm{y}$ ). Depths have been corrected for voids in the core. Declinations were adjusted to produce pre-event declinations of $\sim 0^{\circ}$.

\section{ACKNOWLEDGMENTS}

The authors thank Ji-cheng Shao, Trevor Pattison, Chad Walker, and Joanna Athanassopoulos from UCSB, for assistance in acquiring and plotting this data. This work was funded under JOI/USSP Award No. 155-20842b.

\section{REFERENCES}

Barbetti, M.F., and McElhinny, M.W., 1976. The Lake Mungo geomagnetic excursion. Philos. Trans. R. Soc. London A, 281:515-542.

Cisowski, S.M., 1995. Synthesis of magnetic remanence correlation, Leg 155. In Flood, R.D., Piper, D.J.W., Klaus, A., et al., Proc. ODP, Init. Repts., 155: College Station, TX (Ocean Drilling Program), 701-702.

Flood, R.D., Piper, D.J.W., Klaus, A., et al., 1995. Proc. ODP, Init. Repts., 155: College Station, TX (Ocean Drilling Program).

Freed, W.K., and Healy, N., 1974. Excursions of the Pleistocene geomagnetic field recorded in Gulf of Mexico sediments. Earth Planet. Sci. Lett., 24:99-104.
Henyey, S., Lund, S.P., and Schwarz, M., 1995. Paleomagnetic secular variation records from deep-sea sediments of the Blake/Bahama Outer Ridge (North Atlantic Ocean) during oxygen-isotope Stages 5 and 6 (70-190 ka): further evidence for the relationship between excursions and "normal" secular variation. Eos, 76:F165.

Huxtable, J., and Aitken, M.J., 1977. Thermoluminescent dating of Lake Mungo geomagnetic polarity excursion. Nature, 265:40-41.

King, J.W., Banerjee, S.K., and Marvin, J., 1983. A new rock-magnetic approach to selecting sediments for geomagnetic paleointensity studies: application to paleointensity for the last 4000 years. J. Geophys. Res., 88:5911-5921.

King, J.W., Banerjee, S.K., Marvin, J., and Özdemir, Ö., 1982. A comparison of different magnetic methods for determining the relative grain size of magnetite in natural materials: some results from lake sediments. Earth Planet. Sci. Lett., 59:404-419.

McHargue, L.R., Damon, P.E., and Donahue, D.J., 1995. Enhanced cosmicray production of ${ }^{10} \mathrm{Be}$ coincident with the Mono Lake and Laschamp geomagnetic excursions. Geophys. Res. Lett., 22:659-662.

Raisbeck, G.M., Yiou, F., Bourles, D., and Kent, D.V., 1985. Evidence for an increase in cosmogenic ${ }^{10} \mathrm{Be}$ during a geomagnetic reversal. Nature, 315:315-317. 
Sonett, C.P., Morfill, G.E., and Jokipii, J.R., 1987. Interstellar shock waves and ${ }^{10} \mathrm{Be}$ from ice cores. Nature, 330:458-460.

Thellier, E., and Thellier, O., 1959. Sur l'intensité du champ magnétique terreste dans le passé historique et geologique. Ann. Geophys., 15:285-375.

Thouveny, N., and Creer, K.M., 1992. On the brevity of the Laschamp excursion. Bull. Soc. Geol. Fr. 163:771-780.

Tric, E., Laj, C., Valet, J.-P., Tucholka, P., Paterne, M., and Guichard, F., 1991. The Blake geomagnetic event: transition geometry, dynamical characteristics and geomagnetic significance. Earth Planet. Sci. Lett., 102:1-13.

Tric, E., Valet, J.-P., Tucholka, P., Paterne, M., Labeyrie, L., Guichard, F., Tauxe, L., and Fontugne, M., 1992. Paleointensity of the geomagnetic field during the last 80,000 years. J. Geophys. Res., 97:9337-9351.

\section{A}

A

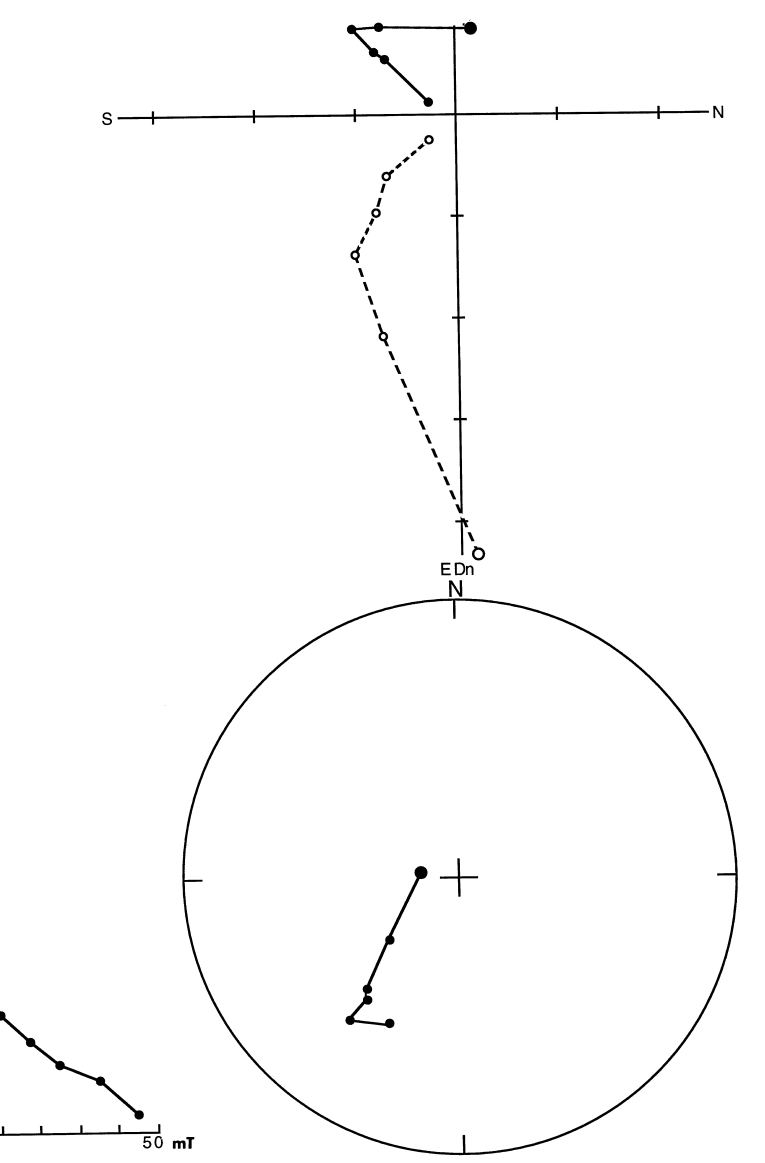

Tucholka, P., Fontugne, M., Guichard, F., and Paterne, M., 1987. The Blake magnetic polarity episode in cores from the Mediterranean Sea. Earth Planet. Sci. Lett., 86:320-326.

Valet, J.-P., and Meynadier, L., 1993. Geomagnetic field intensity and reversals during the past four million years. Nature, 336:234-238.

Date of initial receipt: 4 December 1995

Date of acceptance: 10 June 1996

Ms 155SR-214

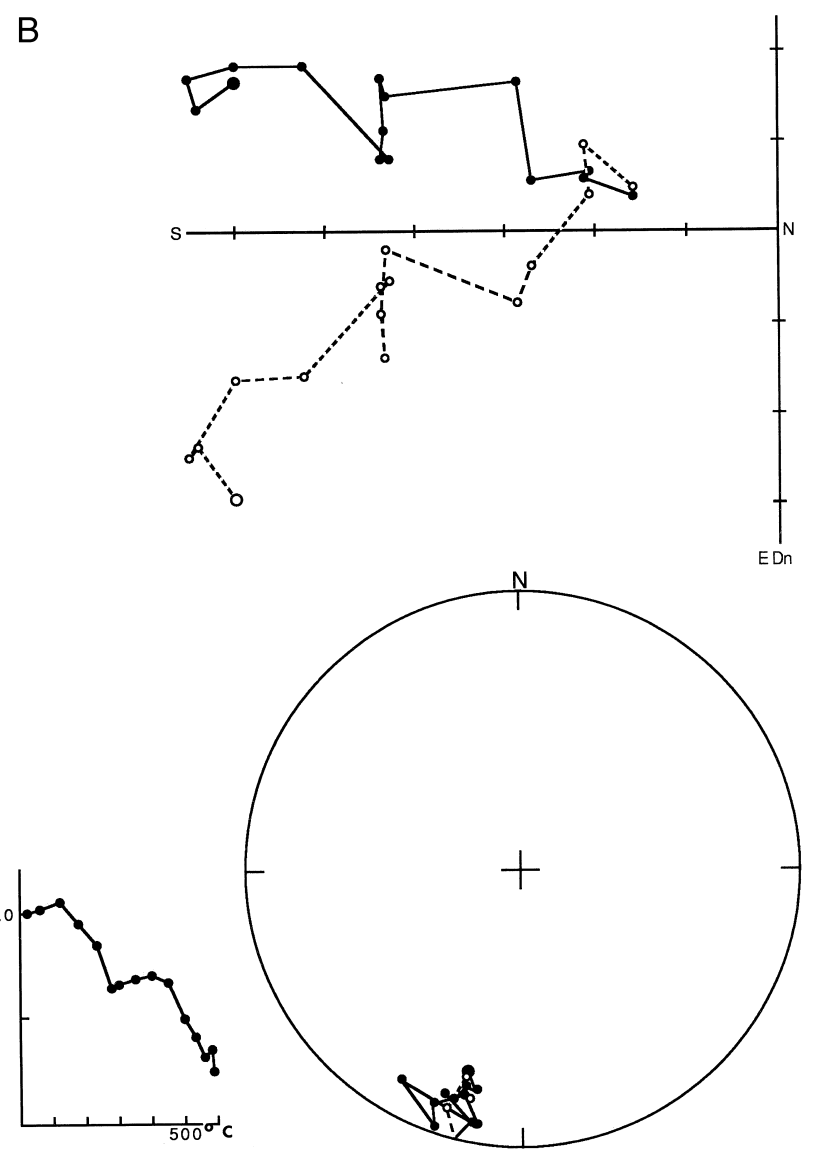

Figure 11. Variation of orthogonal components, normalized intensities, and field vector directions with demagnetization for (A) event Sample 155-946A-15H-3, 87-88 cm (AF) and (B) event Sample 155-946A-15H-3, 75-76 cm (thermal). 


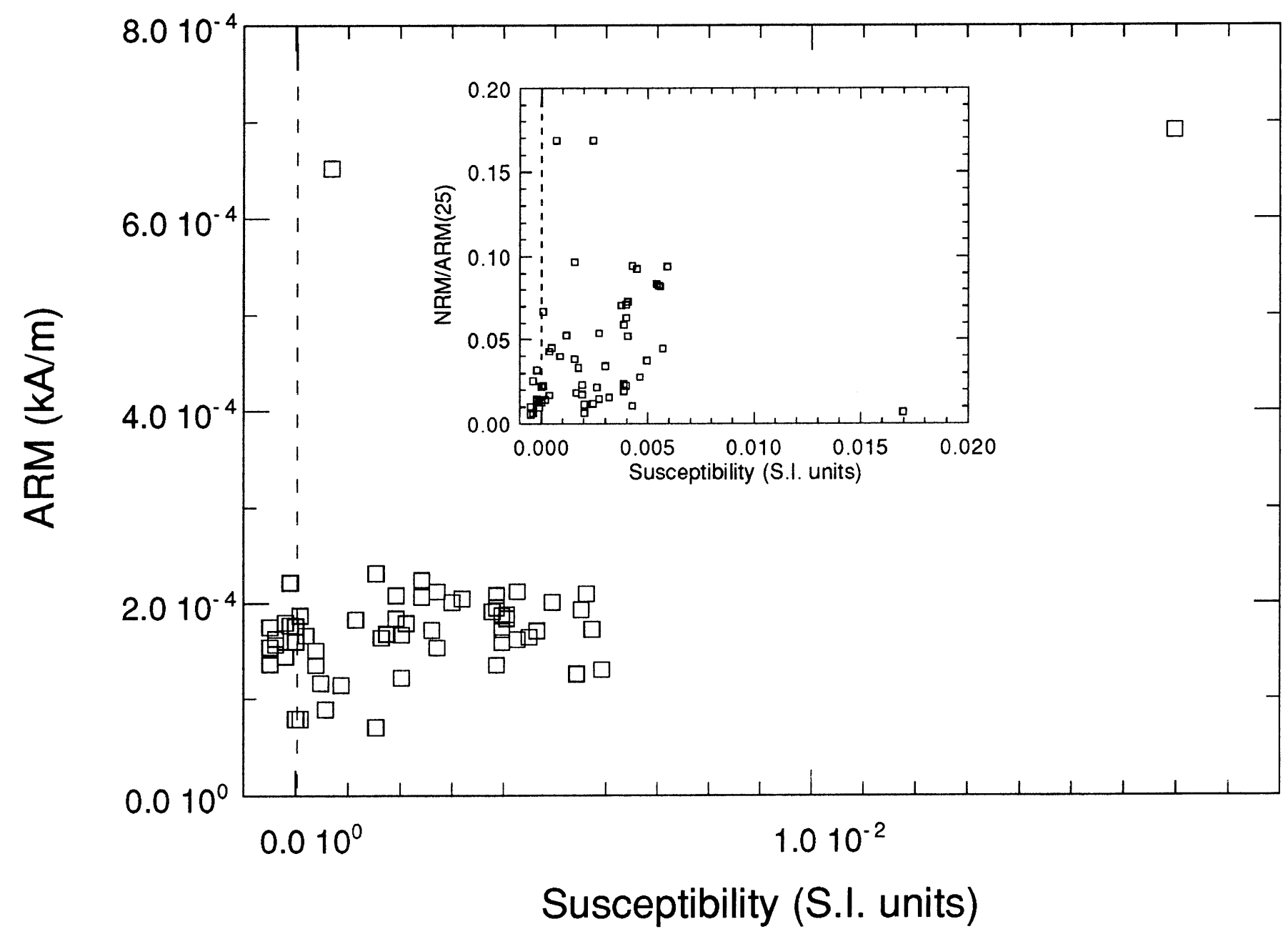

Figure 12. ARM vs. susceptibility plot for Core 155-946A-15H samples included in Figure 10. ARM values are after AF demagnetization to 25 mT. Inset shows the variation of normalized intensity with susceptibility. 

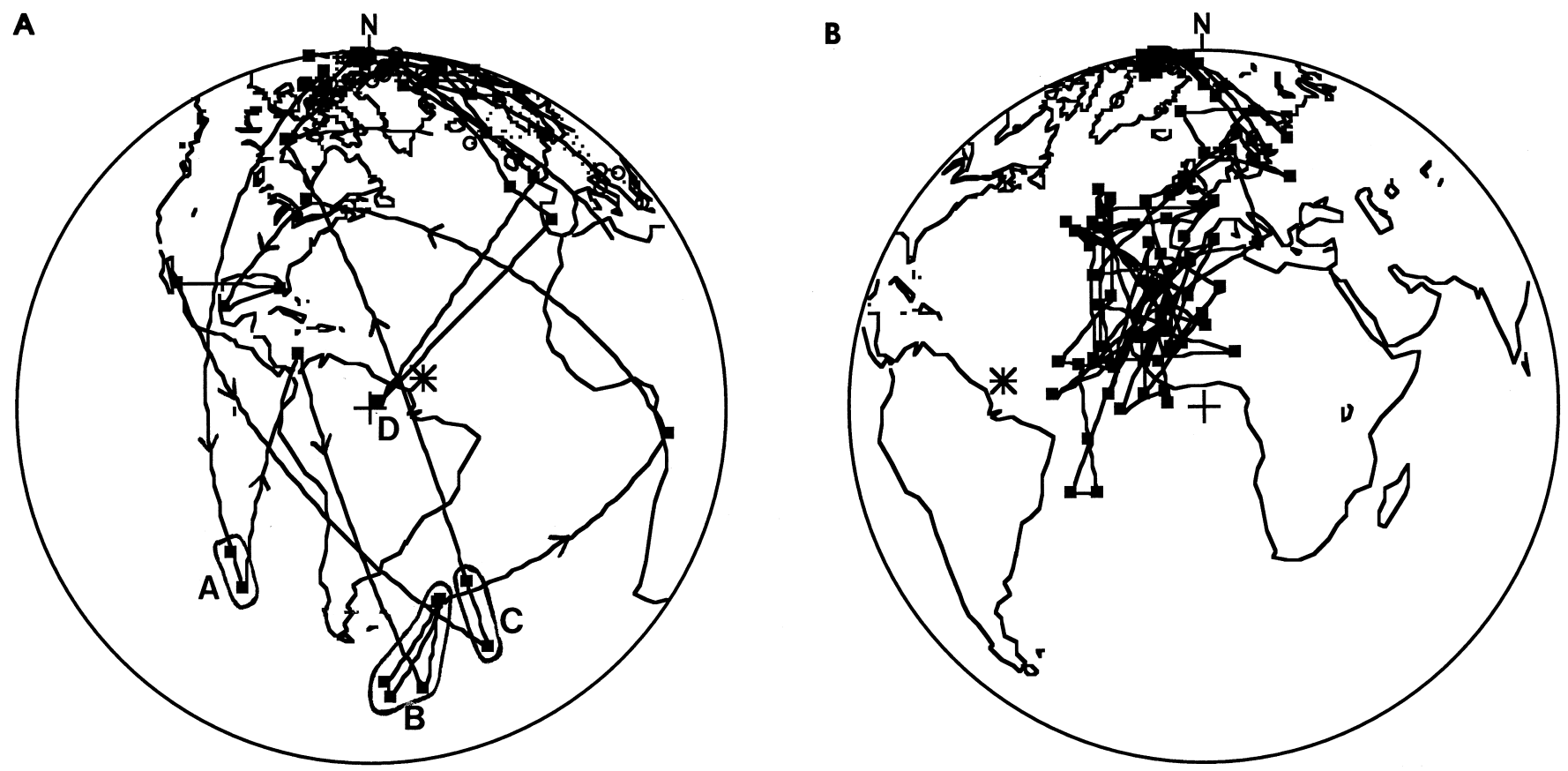

Figure 13. VGP path for the Stage 5 event and excursion recorded in (A) Core 155-946A-15H (A, B, C, and D are features noted in Figure 10) and (B) Core 155-942C-3H. Asterisks denote drilling site locations.

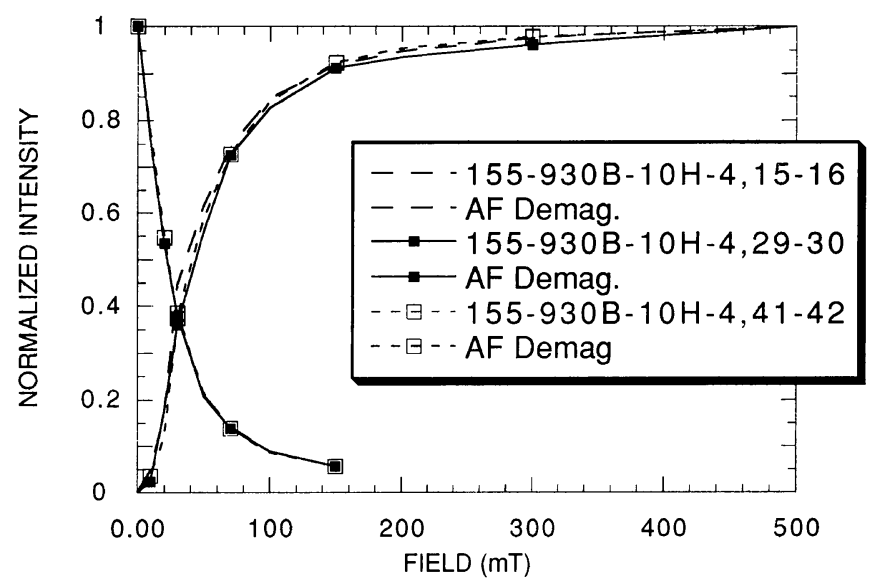

Figure 14. IRM acquisition and AF demagnetization curves for discrete samples from above, at, and below the intensity peak associated with the Core 155-930B-10H excursion. 